\title{
Article
}

\section{Peak Expiratory Flow Rate in Pregnant Women}

\author{
Sunyal DK ${ }^{1}$, Amin MR $^{2}$, Ahmed A ${ }^{3}$, Begum S ${ }^{4}$ Begum $M^{5}$, Rahman $\mathbf{N}^{6}$
}

In the present study peak expiratory flow rate (PEFR) were estimated in pregnant women during different trimester to observe the alteration in air flow rate during pregnancy. This study was carried out in the department of Physiology of Dhaka Medical College from July 2004 to June 2005. For this purpose, total 100 women with age ranged from 25 years to 35 years without any recent history of respiratory diseases were selected and divided into 25 healthy non-pregnant women as control and 75 normal pregnant women as study group. Study group was further divided into 25 in first trimesters, 25 in second trimester and 25 in third trimesters of pregnancy. All the subjects belonged to lower socioeconomic class. The PEFR was estimated by using an automatic spirometer. The measured values and percentage of predicted values of PEFR were estimated during the 1st, 2nd, 3rd trimesters of pregnant women and non-pregnant women. Statistical analysis of data were done by un paired student's “t” test.

The PEFR was significantly lower in both 2nd and 3rd trimester pregnant women than that of nonpregnant women. Again the PEFR was significantly lower in 3rd trimester than that of 1st trimester of pregnant women. There were no statistically significant difference of PEFR between the non-pregnant and 1st trimester; between the 1st trimester and 2nd trimeste ; and between the 2nd trimester and 3rd trimester of pregnant women.

It may be concluded that PEFR were progressively decreased throughout the pregnancy, most likely due to mechanical effects of progressively increased size of uterus that progressively decreases lung volumes and capacities.

Key Words: Expiratory Flow Rate, Pregnancy, Uterus

J Bangladesh Soc Physiol. 2007 Dec;(2): 20-23. For author affiliations, see end of text.

http://www.banglajol.info/index.php/JBSP

\section{Introduction}

D uring normal pregnancy respiratory performance is significantly affected indicated by alterations in lung volumes and capacities ${ }^{1}$. It was observed that due to mechanical effects, progressively increased size of uterus progressively decreases lung volumes and capacities by the 5th month of pregnancy which at term is about $20 \%$ below those of the non-pregnant ${ }^{2}$. It has been observed that changes in the thoracic configuration subsequent to

J Bangladesh Soc Physiol. 2007 Dec;(2): 20-23 progressive increase in the abdominal volume have a moderate effect on respiratory function ${ }^{3}$. Different studies observed changes in PEFR during different trimesters of pregnancy and it was gradually decreased from 1st trimester to 3rd trimester of pregnancy ${ }^{4-5}$. Significant decrease in PEFR during the 2nd trimester has been reported $^{6}$. Again there was statistically significant difference in PEFR among three trimesters of pregnancy ${ }^{7}$. 
According to national Asthma education program $^{8}$ and American college of obstretician and gynecology ${ }^{9}$ measurement of PEFR has been considered as important diagnostic tool for management of pregnancy with asthma. Therefore measurement of PEFR is needed to assess the ventilatory capacity of lungs ${ }^{10}$. Though few data on the effects of pregnancy on pulmonary function is available in other countries by different workers ${ }^{6,7}$. But no published data is available in our country on this aspect.

Therefore, the present study was carried out to observe the changes in PEFR during the different trimesters of normal pregnancy.

\section{Methods}

This cross sectional study was carried out in the department of Physiology of Dhaka Medical College from July 2004 to June 2005.

PEFR were measured in 100 women of aged 25 to 35 year and height between 138 to $161 \mathrm{~cm} .75$ pregnant women were included in experimental group (group B). They were further subdivided into 25 in $1^{\text {st }}$ trimester (group B-I), 25 in $2^{\text {nd }}$ trimester (group B-II) and 25 in $3^{\text {rd }}$ trimester (group B-III). Age and height matched 25 nonpregnant women were taken as control (groupA). All the subjects were selected from different areas of Dhaka city. All the subjects were from lower socioeconomic class with average annual income not exceeding Tk 60,000.00.

All the subjects were excluded for recent respiratory illness. Aim and purpose of the study was explained to the subjects and informed written was taken. Through physical examination of each subject was done and personal and medical history was taken. All information were recorded in a prefixed questionnaire. PEFR were measured by an automatic spirometer.

The observed value of PEFR as percentage of predicted value was calculated. Data were analyzed statistically by unpaired Student's ' $\mathrm{t}$ ' test.

\section{Results}

Age, height, weight and BMI of different groups are presented in Table-I.

Table-I : Mean \pm SD Age, height, weight and BMI of different groups(n=100)

\begin{tabular}{|c|c|c|c|c|c|}
\hline Group & $\mathrm{n}$ & Age (year) & Height (cm) & Weight (kg) & BMI \\
\hline A & 25 & $30.32 \pm 4.01$ & $151.76 \pm 4.73$ & $49.16 \pm 7.73$ & $21.39 \pm 3.50$ \\
\hline B-I & 25 & $29.04 \pm 3.89$ & $151.28 \pm 4.76$ & $48.60 \pm 10.22$ & $21.25 \pm 4.49$ \\
\hline B-II & 25 & $28.40 \pm 3.74$ & $150.68 \pm 5.97$ & $46.96 \pm 9.22$ & $20.62 \pm 3.53$ \\
\hline B-III & 25 & $29.08 \pm 3.29$ & $150.68 \pm 4.92$ & $51.64 \pm 9.82$ & $22.74 \pm 4.04$ \\
\hline \multicolumn{6}{|c|}{ Statistical analysis } \\
\hline Groups & P value & P value & P value & P value & \\
\hline A vs B-I & $>0.10^{\mathrm{ns}}$ & $>0.50^{\mathrm{ns}}$ & $>0.05^{\mathrm{ns}}$ & $>0.50^{\mathrm{ns}}$ & \\
\hline A vs B-II & $>0.05^{\mathrm{ns}}$ & $>0.10^{\mathrm{ns}}$ & $>0.10^{\mathrm{ns}}$ & $>0.10^{\mathrm{ns}}$ & \\
\hline A vs B-III & $>0.10^{\mathrm{ns}}$ & $>0.10^{\mathrm{ns}}$ & $>0.10^{\mathrm{ns}}$ & $>0.10^{\mathrm{ns}}$ & \\
\hline B-I vs B-II & $>0.50^{\mathrm{ns}}$ & $>0.50^{\mathrm{ns}}$ & $>0.50^{\mathrm{ns}}$ & $>0.50^{\mathrm{ns}}$ & \\
\hline B-I vs B-III & $>0.50^{\mathrm{ns}}$ & $>0.50^{\mathrm{ns}}$ & $>0.10^{\mathrm{ns}}$ & $>0.10^{\mathrm{ns}}$ & \\
\hline B-II vsB-III & $<0.10^{\text {ns }}$ & $>1.00^{\mathrm{ns}}$ & $>0.50^{\mathrm{ns}}$ & $>0.05^{\mathrm{ns}}$ & \\
\hline
\end{tabular}

$\mathrm{A}=$ healthy non-pregnant women $\mathrm{B}-\mathrm{I}$ = pregnant women in 1st trimester, $\mathrm{B}-\mathrm{II}=$ pregnant women in 2nd trimester B - III = pregnant women of 3rd trimester, $\mathrm{n}$ = number of subjects, $\mathrm{P}$ values were obtained by unpaired Student's “t” test, ns = non significant 


\section{Article}

The differences among the groups in relation to age, height, weight and BMI were not statistically significant.

Measured values of PEFR and there percentage of predicted values were presented in Table-II.

Table - II: Mean $( \pm$ SD) of measured values and $\%$ of predicted values of PEFR in different groups $(n=100)$

\begin{tabular}{|c|c|c|c|}
\hline Groups & $\mathrm{N}$ & PEFR (Liter) & $\begin{array}{l}\text { PEFR \% } \\
\text { of predict }\end{array}$ \\
\hline A & 25 & $428 \pm 2.07$ & $71.84 \pm 33.55$ \\
\hline B-I & 25 & $409 \pm 1.79$ & $66.40 \pm 29.82$ \\
\hline B-II & 25 & $323 \pm 1.52$ & $54.04 \pm 24.43$ \\
\hline \multirow[t]{2}{*}{ B-III } & 25 & $311 \pm 1.30$ & $52.92 \pm 22.58$ \\
\hline & & \multicolumn{2}{|c|}{ Statistical analysis } \\
\hline \multicolumn{2}{|l|}{ Group } & P value & P value \\
\hline \multicolumn{2}{|c|}{ A vs B - I } & $>0.50^{\mathrm{ns}}$ & $0.703^{\mathrm{ns}}$ \\
\hline \multicolumn{2}{|c|}{ A vs B - II } & $<0.05^{*}$ & $0.037^{*}$ \\
\hline \multicolumn{2}{|c|}{ A vs B - III } & $<0.05^{*}$ & $0.024^{*}$ \\
\hline \multicolumn{2}{|c|}{ B-I vs B - II } & $>0.50^{\mathrm{ns}}$ & $0.068^{\mathrm{ns}}$ \\
\hline \multicolumn{2}{|c|}{ B-I vs B - III } & $<0.05^{*}$ & $0.044^{*}$ \\
\hline \multicolumn{2}{|c|}{ B-II vs B - III } & $>0.50^{\mathrm{ns}}$ & $0.867^{\text {ns }}$ \\
\hline
\end{tabular}

$\mathrm{A}=$ healthy non-pregnant women $\mathrm{B}-\mathrm{I}=$ pregnant women in 1st trimester, $\mathrm{B}-\mathrm{II}=$ pregnant women in 2nd trimester B - III = pregnant women of 3rd trimester, $\mathrm{n}=$ number of subjects, $\mathrm{P}$ values were obtained by unpaired Student's "t" test, * = significantat $\mathrm{p}<0.05$, ns $=$ non significant

The mean PEFR in pregnant women during all three trimester were lower than those of non pregnant women and it was statically significant $(\mathrm{p}<0.05)$ except in first trimester.

The PEFR values were progressively decreased during pregnancy from 1st trimester to 3rd trimester. The PEFR was significantly $(<0.05)$ decreased during 2nd trimester $\&$ 3rd trimester compared to non-pregnant women.
Peak Expiratory Flow Rate in Pregnant Women

Again PEFR was significantly $(<0.05)$ decreased during 3rd trimester compared to 1st trimester of pregnant women (Table-II).

The difference in PEFR between non-pregnant and 1st trimester and among different trimesters were no statistically significant

\section{Discussion}

The mean measured and \% of predicted values of PEFR was significantly $(<0.05)$ lower during 2nd trimester and 3rd trimester compared to nonpregnant women and in 3rd trimester compared to 1st trimester. Our results are in agreement with those of other workers ${ }^{11}$. On the other hand no statistically significant differences in PEFR among the three trimesters of pregnancy were observed ${ }^{9}$.

In the present study, progressively decreased value of PEFR were observed from 1st trimester to 3rd trimester and the result was partially significant. Similar findings were also observed by some other workers ${ }^{6,7}$. It has been suggested that significant reduction in PEFR during pregnancy is most likely due to lesser force of contraction of the expiratory muscles like anterior abdominal muscles and internal intercostals muscles in this state. ${ }^{7,13}$. More over, progressively reduced value of PEFR in three trimesters of pregnancy may be attributed to the mechanical effects of enlarged gravid uterus reducing vertical dimension by limiting movement of diaphragm ${ }^{6}$. In addition some degree of obstruction to the expiratory flow, especially late in pregnancy also contributes. ${ }^{12}$. Some studies suggest, inadequate nutrition due to morning sickness, altered eating habits associated with advancing gestation that resulted in muscular weakness and the lesser force of contraction of main expiratory muscles ${ }^{10}$ In the present study the poor socioeconomic condition of the subjects also support this feature.

\section{Conclusion}

From the present study, it may be concluded that PEFR were significantly decreased in 2nd

J Bangladesh Soc Physiol. 2007 Dec;(2): 20-23 
trimester and 3rd trimester due to poor nutrition as all of them belonged to lower middle poor socioeconomic status. Poor nutritional status leads to poor growth of muscles and development of lungs and consequently decreased pulmonary functions.

\section{Author Affiliations}

*1. Dr. Dipok Kumar Sunyal, Assistant Professor, Department of Physiology, Enam Medical College, Savar, Dhaka, Bangladesh

2. Prof. Dr. Md. Ruhul Amin, Professor and Head, Department of Physiology, Dhaka Medical College, Dhaka, Bangladesh

3. Prof. Abeda Ahmed, Professor and Head, Department of Physiology, Comilla Medical College, Comilla, Bangladesh

4. Dr. Shameema Begum, Assistant Professor, Department of Physiology, Dhaka Medical College, Dhaka, Bangladesh

5. Assistant Professor, Department of Physiology, Dhaka Medical College, Dhaka, Bangladesh

6. Assistant Professor, Department of Physiology, Begum Khaleda Zia Medical college, Dhaka, Bangladesh

* for correspondence

\section{References}

1. DeCherney AH and Pernoll. Maternal physiology during pregnancy. In : Current Obstetrics \& Gynecologic Diagnosis \& Treatment. Ninth Edition. 2003 : 159-160.

2. Eng M, Butler J and Bonica J J. Respiratory function in pregnant obese women. Am J Obstet Gynecol 1975 ; 123(3) : 241-245.

3. Clerici C. Modifications of respiratory function during pregnancy. Rev Pneumol Clin 1999; 55(5) : 307-311.
4. Rasheed B, Hussain K and Hussain S. PEFR in relation to phases of pregnancy. Indian J Physiol Pharmacol 2000 ; 44 (4) : 511-512.

5. Puranik BM, Kurhade GA, Kaore SB, Patwardhan SA, Kher JR. PEFR in pregnancy : an ongitudinal study. Indian J Physiol Pharmacol 1995 ; 39 (2) : 135-139.

6. Rasheed B, Mansoor A and Hussain S. Incentive Spirometry and PEFR in different phases of pregnancy. Indian J Physiol Pharmacol 2002 ; 46 (1) : 126-128.

7. Spiropoulos K, Prodromaki E, Tsapanos V. Effect of body position on $\mathrm{PaO}_{2}$ and $\mathrm{PaCO}_{2}$ during pregnancy. Gynecol Obstet Invest 2004 ; 58 : 22 -25.

8. National Asthma Education Program.Report of the working group on asthma in pregnancy. Management of asthma during pregnancy.NIH publication no.933279.Bethseda, Maryland: Department of health and human services,1993.

9. American college of obstreticians and gynecologist. Pulmonary disease in pregnancy.ACOG technical bulletin no.224.Washington DC:1996.

10. Brancazio LR, Laifer SA, Schwartz T. Peak Expiratory Flow Rate in normal pregnancy. Obstet Gynecol. 1997 ; 89 (3) : 383-386.

11. Arroyo MA, Delaney J, Welch R. Normal lung function assessment during pregnancy. J Obstet Gynaecol 1999 ; 19 (suppl 1) : 43.

12. Norregaard O, Schultz P, Ostergaard A and Dahl R. Lung function \& Postural changes during pregnancy. Respir Med. 1989 ; 83 : 467-70.

13. Phatak MS and Kurhade GA. A longitudinal study of antenatal changes in lung function tests and importance of postpartum exercises in their recovery. Indian $\mathrm{J}$ Physiol Pharmacol 2003 ; 47(3) : 352-356. 